\title{
Window frame thermal performance simulation. Suitable methods according to climate and technology
}

\author{
Simulación de eficiencia energética de marcos de ventana. Métodos adecuados según el clima y \\ la tecnología
}

Maureen de Gastines (Main and Corresponding Author)

Instituto de Ambiente, Hábitat y Energía (INAHE) - CONICET

Av. Ruiz Leal $s / n$, Mendoza (Argentina)

mdegastines@mendoza-conicet.gob.ar

Érica Correa

Instituto de Ambiente, Hábitat y Energía (INAHE) - CONICET

Av. Ruiz Leal s/n, Mendoza (Argentina)

ecorrea@mendoza-conicet.gob.ar

\section{Andrea Pattini}

Instituto de Ambiente, Hábitat y Energía (INAHE) - CONICET

Av. Ruiz Leal s/n, Mendoza (Argentina)

apattini@mendoza-conicet.gob.ar

Manuscript Code: 885

Date of Acceptance/Reception: 24.11.2017/11.02.2017

DOI: 10.7764/RDLC.17.1.112

\begin{abstract}
Within the framework of window labelling system elaboration in Argentina, this article questions the suitability of replicating calculation procedures from other countries with different climatic and technological contexts. This paper analyzes the methodological differences between existing standards for calculating window frame U-factor. It focuses on the impact of the radiation model applied on the frame outside boundary. Simulations were performed on different window frames under three sets of environmental conditions, first using the NFRC blackbody radiation model at the outside boundary, then using the ISO 15099 detailed radiation model. The comparison of the resulting U-factors shows significant differences (up to $12.7 \%$ ) between both models. The impact of outside boundary radiation model choice increases with the non-planarity of outside frame boundary and decreases at high wind speeds. According to these results, the ISO 15099 detailed radiation model should be used on both sides of the frame, in order to maximise the accuracy of non-planar frames thermal transmittance calculation under any environmental conditions.
\end{abstract}

Key words: fenestration, THERM, U-factor, numerical calculation, labelling, environmental conditions, radiation model.

Resumen

En el marco de la elaboración de un sistema de certificación de ventanas en Argentina, este artículo cuestiona la validez de reproducir procedimientos de cálculo de otros países con un contexto climático y tecnológico diferente. Se analizan las diferencias metodológicas entre los estándares existentes para calcular el factor U de los marcos de ventanas. En particular, se examina el impacto del modelo radiativo empleado en la superficie externa del marco. Se simularon diferentes marcos de ventana bajo tres conjuntos de condiciones de entorno, primero utilizando el modelo llamado de cuerpo negro de la NFRC, y luego aplicando el modelo radiativo detallado de la norma ISO 15099. La comparación entre los factores U resultantes evidencia diferencias importantes (hasta un $12.7 \%$ ) entre ambos modelos. El impacto de la elección del modelo radiativo exterior aumenta a medida que disminuye la compacidad exterior del marco, y se reduce en caso de altas velocidades de viento. De acuerdo a estos resultados, el modelo radiativo detallado de ISO 15099 debe ser utilizado en ambas fronteras del marco, para optimizar la precisión del cálculo de la transmitancia térmica de los marcos de ventana de baja compacidad bajo cualesquiera condiciones de entorno.

Palabras clave: carpinterías, THERM, Factor U, cálculo numérico, certificación, condiciones ambientales, modelo de radiación.

Introduction

Energy rating procedures are being developed worldwide in order to reduce energy consumption. In particular, product energy efficiency norms and labels are being used to inform the consumer and encourage the development of more efficient and market-competitive technologies (A. Pattini, Correa, Villalba, Fernández Llano, \& de Gastines, 2014). Initially implemented in products like household appliances, energy ratings were extended to the building sector, through whole building labelling (based on total energy consumption) or through building components rating (Andaloro, Salomone, loppolo, \& Andaloro, 2010; Lamberts, Goulart, Carlo, \& Westphal, 2007; Pérez-Lombard, Ortiz, González, \& Maestre, 2009).

Window labelling started in the United States in 1993, and was applied in different countries around the world since then. It is mandatory in the European community since 2010 (A. E. Pattini, Villalba, Correa, \& Llano, 2013). In Sweden, 
the whole energy efficient windows development process resulted in an improvement in best technology of Swedish windows' U-factors from $1.8 \mathrm{~W} / \mathrm{m}^{2} \mathrm{~K}$ in the 1970 s to $0.7 \mathrm{~W} / \mathrm{m}^{2} \mathrm{~K}$ in 2010 (Kiss \& Neij, 2011). Currently, the Argentinean Institute for Standardization and Certification (IRAM) is working on a label for windows in Argentina. To this day, the typical windows used in this country are aluminium-framed slider windows without thermal break combined with single glazing. Those windows have U-factors around $7 \mathrm{~W} / \mathrm{m}^{2} \mathrm{~K}$ (de Gastines, Villalba, \& Pattini, 2016). The massive use of such poorly insulated windows constitutes a drastic technological backwardness, which is why the introduction of a window rating and labelling procedure for Argentina is crucial.

Argentina can be divided into very different climatic zones. The northern region is characterized by hot temperatures and high levels of solar radiation. The south of the country has very cold winters and high wind speeds, whereas the centre region has both warm summers and cold to temperate winters. This region includes the most populated cities of Argentina (Buenos Aires, Cordoba, Rosario, Mendoza), which are associated with the greatest window demand. In particular, the cities present characteristics of urban heat islands, where mean radiant temperatures higher than $100 \circ \mathrm{C}$ have been measured, combined with air temperatures of $35^{\circ} \mathrm{C}$ and wind velocities under $1 \mathrm{~m} / \mathrm{s}$ (Alchapar \& Correa, 2016). However, the main rating standards have been elaborated mostly in countries with cold climates and low solar radiation (Avasoo, 2007). The differences of climatic and technological context raise doubts about the validity of applying in Argentina methodologies developed elsewhere.

Window energy efficiency labels are based on the calculation of thermal performance indices like the window $U$-factor and Solar Heat Gain Coefficient. These indices can be calculated through measurement or detailed two-dimensional numerical methods. Simulation is a cheaper and faster option, and is the method used in the United States to certify windows.

The calculation of thermal indices is more complex for frames than for glazings, since the latters can be modelled as a one-dimensional problem, whereas frames have generally non-planar geometries, and then require two- or threedimensional characterization. Since they contain cavities and grooves as well as self-viewing surfaces, convective and radiative exchanges are complex, and the assumptions for the definition of boundary conditions must be considered carefully. When it comes to frames, the most relevant thermal index is the U-factor. Although solar gain also occurs through opaque surfaces, it is assumed to be negligible compared to solar gain through the glazing. For those reasons, in this work we focus on frame U-factor calculation.

\section{Description of the Problem}

Two main standards exist for the calculation of the thermal transmittance of window frames: ISO 15099 and ISO $10077-$ 2 (ISO 15099, 2003; ISO 10077-2, 2003). Also, two fenestration energy rating systems, National Fenestration Rating Council (NFRC, 2004) and Passive House, developed their own calculation procedure, which are based on ISO 15099 and ISO 10077-2 respectively. Those standards differ in calculation methodologies and in standard conditions (temperatures, film coefficients). Therefore, there are discrepancies between the frame $\mathrm{U}$-values calculated under the different standards (RDH Building Engineering, 2014). For the purpose of certification, consistent environmental conditions are needed in order to compare the fenestration systems performance under the same conditions. For example, Cordero et al. studied the thermal performance of an innovative frame-integrated unitised curtain wall and compared it to conventional systems by contrasting their U-factors, calculated according to the NFRC methodology and environmental conditions (Cordero, García-Santos, \& Overend, 2015).

However, when it comes to estimating component thermal performance under real conditions, defining representative boundary conditions is important. M. de Gastines, Villalba and Pattini (2014) studied the influence of boundary conditions on U-factor by comparing the values obtained according to NFRC environmental conditions $\quad\left(-18^{\circ} \mathrm{C}\right.$ as outside temperature and $26 \mathrm{~W} / \mathrm{m}^{2} \mathrm{~K}$ as outside convective coefficient) and under more representative conditions for Mendoza, which is a city with temperate winters and low wind speed (outside temperature of $2.8^{\circ} \mathrm{C}$ and outside convective coefficient of $9.45 \mathrm{~W} / \mathrm{m}^{2} \mathrm{~K}$, corresponding to winter average extreme conditions). They found differences around $20 \%$ between the studied windows U-factors.

These discrepancies indicate the importance of defining adequate boundary conditions for U-factor calculation, especially when the average climatic conditions are very different compared to the standards' boundary conditions. For example, NFRC outside convective coefficient $\left(26 \mathrm{~W} / \mathrm{m}^{2} \mathrm{~K}\right)$ corresponds to a wind speed of $5.5 \mathrm{~m} / \mathrm{s}$, which may be representative of the Patagonia region, but is twice higher than the average wind speed in the centre region of the country (IRAM, 2012). In such cases, calculating the U-factor based on local climatic conditions is important, since: 
1) Indices not only are used to compare different fenestration technologies, but also as if they were constant properties, in different simulation software and energy efficiency calculations.

2) Most fenestration rating systems are based on a heat balance (Karlsson, Karlsson, \& Roos, 2001; Nielsen, Duer, \& Svendsen, 2001; A. Pattini et al., 2014), i.e. on the algebraic sum of heat gain and loss through the window components. Using the NFRC boundary conditions instead of more representative conditions can result in significantly higher U-factors, which means that, in the winter heat balance, more weight is given to thermal loss than solar gain. This could lead to different window ranking, especially in regions with high solar radiation, temperate or warm climate and low wind speed (e.g. north and central-west of Argentina).

For these reasons, the calculation procedure of frame U-factors should be adapted to the specific climatic conditions of the country where the frame is going to be installed. This is particularly important for countries where non-planar aluminium thermally unbroken frames are massively used (like Argentina), since the thermal performance of these frames highly depends on film coefficients (de Gastines et al., 2016).

This work aims to analyze the differences between the main standards for frame U-factor calculation by numerical methods, and formulate recommendations for an adequate simulation procedure for rating applications, taking into account local climatic and technological context.

\section{State of the Art}

The frame U-factor can be defined and calculated in two ways. Both of them are described in ISO 15099 and differ in how they deal with edge effects at the frame/glazing interface. The first alternative, described in ISO 10077-2 as well, consists in calculating the frame $\mathrm{U}$-factor by replacing the glazing by an insulation panel. Edge effects are accounted for in a linear transmittance value associated to the border between the frame and the glazing. The second alternative is to calculate directly the frame U-factor with the glazing in place (which means that the resulting value includes part of the edge effects) and define a $63.5 \mathrm{~mm}$ edge-of-glass region from the glazing/frame sightline, which is affected by the rest of edge effects. Blanusa et al. (2007) compared U-factors obtained from both methods for windows of different sizes, using THERM. They found small discrepancies (under 3\%, and negligible for large window) in the overall thermal transmittance value when using identical boundary conditions.

Internal frame cavities are treated as though they contain an opaque solid, which is assigned an effective conductivity that accounts for both radiative and convective heat transfer. The convective and radiative correlations used for the effective conductivity calculation are simplified in ISO 10077-2 and more detailed in ISO 15099. Noyé, Laustsen, and Svendsen (2004) examined through simulations in THERM the impact of the radiative model used in internal cavities by both standards. They concluded that the simplified model described in ISO 10077-2 does not produce valid results compared to measured values, whereas the detailed, view-factors-based ISO 15099 radiation model gives results which fit well with experimental results.

The impact of environmental conditions on heat transfer depends on how the boundary conditions are defined, in particular, whether slightly ventilated cavities are considered or not and according to which criteria. Both standards ISO 15099 and ISO 10077-2 define slightly ventilated as grooves or cavities connected to the external or internal environments by an opening greater than $2 \mathrm{~mm}$ but not exceeding $10 \mathrm{~mm}$. NFRC procedure adopts the same considerations, but only on the outside of frame. The effective conductivity of a slightly ventilated cavity is twice that of an unventilated air cavity of the same size.

Regarding film coefficients, the standards assumptions are different. ISO 10077-2 defines internal and external surface resistance values, which include the combined effects of convection and radiation. ISO 15099 addresses convection and radiation at frame boundaries separately, and provides correlations to calculate the convective and radiative coefficients as a function of various parameters, like wind velocity, height of the fenestration system, sky view factor, etc. It also describes a two-dimensional, detailed radiation model, based on the calculation of view factors between the different segments of the window and surroundings.

The impact of using or not a detailed radiation model based on view factor calculation on the inside of the frame was studied by Griffith, Curcija, Turler, and Arasteh (1998). They found that using the detailed radiation model is more accurate than using fixed film coefficients, and gives a much better correspondence between simulation results and measurements of frame thermal transmittance. NFRC 100 recommends its use for the inside window boundary, but uses a blackbody radiation model at the outside boundary, which considers that every segment of the frame and glazing is fully exposed to longwave radiation from the surroundings (view factor to the surroundings equal to 1 ). According to this assumption, linearized radiative coefficients are calculated based on local surface temperatures and the mean 
radiant temperature. However, ISO 15099 mentions that the blackbody radiation model is not suitable for non-planar fenestration systems (i.e. whose ratio of total to projected boundary surface area on the internal/external side is greater than 1.25), since they have self-viewing surfaces.

ISO 15099 also offers a simplified alternative to the detailed radiation model, which accounts for self-viewing surfaces through the use of reduced emissivity $\varepsilon_{\text {red }}$ (Equations 3 and 4).

$$
\begin{gathered}
\varepsilon_{r e d}=F_{r} \varepsilon \\
F_{r}=\frac{1}{1+\varepsilon_{g}\left(\frac{A_{s}}{A_{p}}-1\right)}
\end{gathered}
$$

Where $\varepsilon$ is the true surface emissivity, $F_{r}$ is the reduction factor, $\varepsilon_{g}$ is the glazing emissivity, $A_{s}$ is the window developed surface area, and $A_{p}$ is the window opening area.

\section{Simulation criteria}

Regarding the consideration of edge effects at the frame/glass interface, as previously mentioned, the methodology employed does not significantly affect the resulting U-factor. The second alternative for frame U-factor calculation in ISO 15099 has the advantage of being a faster method for calculating the total window U-factor (only one simulation with the glazing in place is needed, whereas the other method requires two simulations, with the insulation panel and with the glazing). However, the resulting value includes part of the edge effects, which is a problem for the characterization of the frame alone (without glazing). For this reason, we recommend the use of the first alternative for frame rating purpose.

With regard to internal frame cavities modelling, convective and radiative exchanges correlations should be defined according to ISO 15099. Regarding convective exchanges at the inside and outside boundaries of the frame, defining slightly ventilated cavities allow for differentiation of areas where convective exchanges are close to zero from areas fully exposed to inside or outside convective coefficient, which is a more accurate characterization. This is why slightly ventilated cavities should be defined on both sides of the frame, according to ISO 15099 and ISO 10077-2 criteria.

Regarding radiation modelling, the ISO 15099 detailed radiation model used on the inside boundary of the frame was proven to be more accurate than using a fixed radiative coefficient. According to ISO 15099 recommendations, this model should be used on both sides of the frame, since most Argentinean windows are highly non-planar (de Gastines et al., 2016). In contrast, NFRC procedure recommends using the black body radiation model instead of detailed radiation model on the frame outside boundary. This discrepancy between both standards is discussed in this paper.

Methodology

In order to evaluate the impact on U-factor calculation of using or not a detailed (view-factors-based) model at the outside boundary of the frame, simulations were performed on different window frames, first using the NFRC blackbody radiation model on the outside boundary, then using the ISO 15099 detailed radiation model. Afterwards, the results were compared.

For frame thermal performance simulation, the WINDOW 6.3/THERM 6.3 package (Robin et al., 2011) for conducting two-dimensional simulations (based on the finite elements method) was used, since it has been widely reviewed and validated (Duer, Svendsen, Moller Mogensen, \& Birck Laustsen, 2002; Hilderson, 2011; Noyé et al., 2004). Besides, it is continuously actualized, and extensively used in the industry (it is the approved software package for window certification in the United States). THERM is derived from NFRC methodology, but is flexible and can be adapted to other approaches.

When we tried to use simultaneously the detailed radiation ("Automatic Enclosure") model on both sides of the window, the software gave inconsistent results (around $2 \mathrm{~W} / \mathrm{m}^{2} \mathrm{~K}$ for aluminium frames without thermal break). It seems that there is a bug in the source code which has not been resolved, probably because the software is being used and actualized mainly for certification purpose in United States according to NFRC 200, which uses different radiation models on each side of the window. For this reason, an artifice was used to estimate the frames U-factor according to ISO 
recommendation, inspired from ISO 15099 simplified alternative to detailed radiation model. This consists in using reduced emissivity values to reproduce the effect of self-viewing surfaces (Since the segments of the frame profile do not have a complete $\left(180^{\circ}\right)$ vision of the surroundings, but exchange longwave radiation with other surfaces of the frames generally at a similar temperature, the resulting radiative coefficient is lower than the one calculated through the blackbody radiation model). The determination of inside and outside reduced emissivity values is done by trial and error. First, the frame is simulated using the detailed radiation model on the inside and the blackbody radiation model on the outside. The resulting frame U-factor is hereafter called UfO. Next, the simulation is run using the blackbody radiation model on both sides, and assigning different values of reduced emissivity to the inside boundary, until the resulting frame U-factor is equal to UfO. Using the corresponding reduced emissivity together with the blackbody radiation model is therefore assumed to be equivalent to using the detailed radiation model with the true surface emissivity. This way, it is possible to simulate the frame using the detailed radiation model on the outside, while considering at the same time the effects of self-viewing surfaces on the inside, in order to calculate a more accurate value for the frame U-factor, hereafter called Uf1.

\section{Case studies}

At first, rectangular solid frames were selected in order to analyze the influence of conductivity and shape factor $\eta$ (defined as the ratio between inside/outside frame projection perpendicular to the plane of the window, and frame projected area in the plane of the window). For simplification, the inside and outside projections were considered identical, and the frames width was set to $10 \mathrm{~cm}$. Different shape factor values $(0,0.15,0.25,0.5,0.75,1)($ Table 1$)$ and conductivities values $(0.03 ; 0.15 ; 0.5 ; 10 ; 100 \mathrm{~W} / \mathrm{mK})$ were selected. An emissivity of 0.9 was considered, which is representative for painted frames (Asdrubali, Baldinelli, \& Bianchi, 2013).

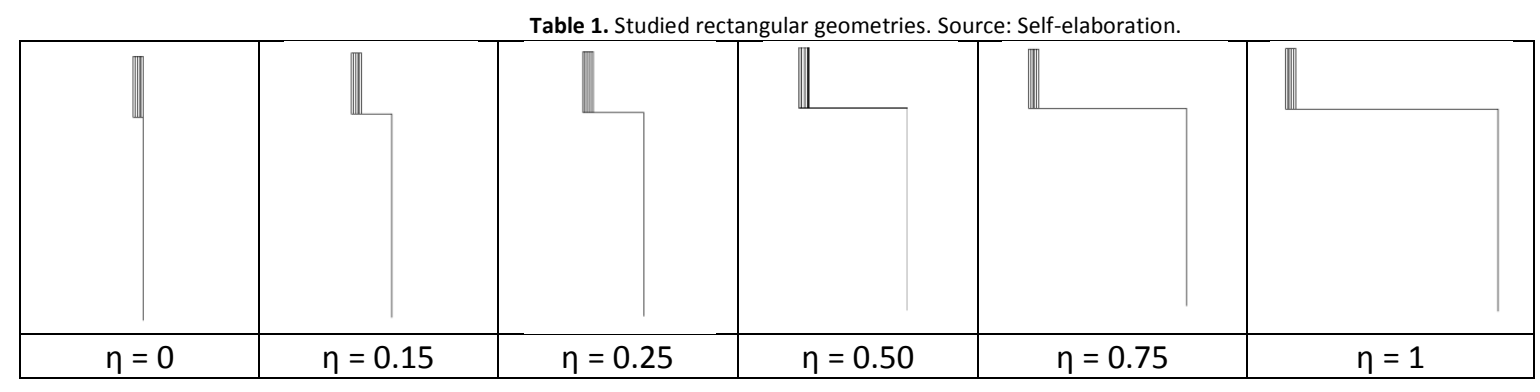

Then, different frames from Argentinean manufacturers were selected as case studies, made of different materials (thus with different conductance values), single or double-glazed. Slider typologies were chosen because they generally have more complicated, highly non-planar geometries. For simplification, only one section of each frame was analyzed, with internal sash and with external sash. The characteristics of the selected case studies are detailed in Table 2 . The inside and outside compactness factors $x_{i}$ and $x_{0}$ are indicated, as they are more representative parameters of frame thermal performance than shape factors (de Gastines et al., 2016). They are defined as the ratio between the frame projected height and the length of the inside and outside (respectively) profile boundaries (considering slightly ventilated cavities). In all frame sections, the outside pane of the window is on the left side of the picture.

\section{Environmental conditions}

Three sets of environmental conditions were defined. The first one (C1) corresponds to the conditions used in NFRC methodology (very cold winter). The second one (C2) considers more usual outside temperatures and film coefficient. The third one (C3) corresponds to a hot summer situation representative of northern and central-western Argentina. Table 3 shows the characteristics of each environmental condition.

In this work, the impact of using or not the detailed radiation model on the outside of the window is analyzed, by comparing the UfO values (calculated with a blackbody radiation model on the outside) and Uf1 values (calculated with a detailed radiation model on both sides) obtained for the different case studies, which include different frame materials and geometries, as well as different environmental conditions. 
Table 2. Characteristics of the real frames selected as case studies. Source: Self-elaboration.

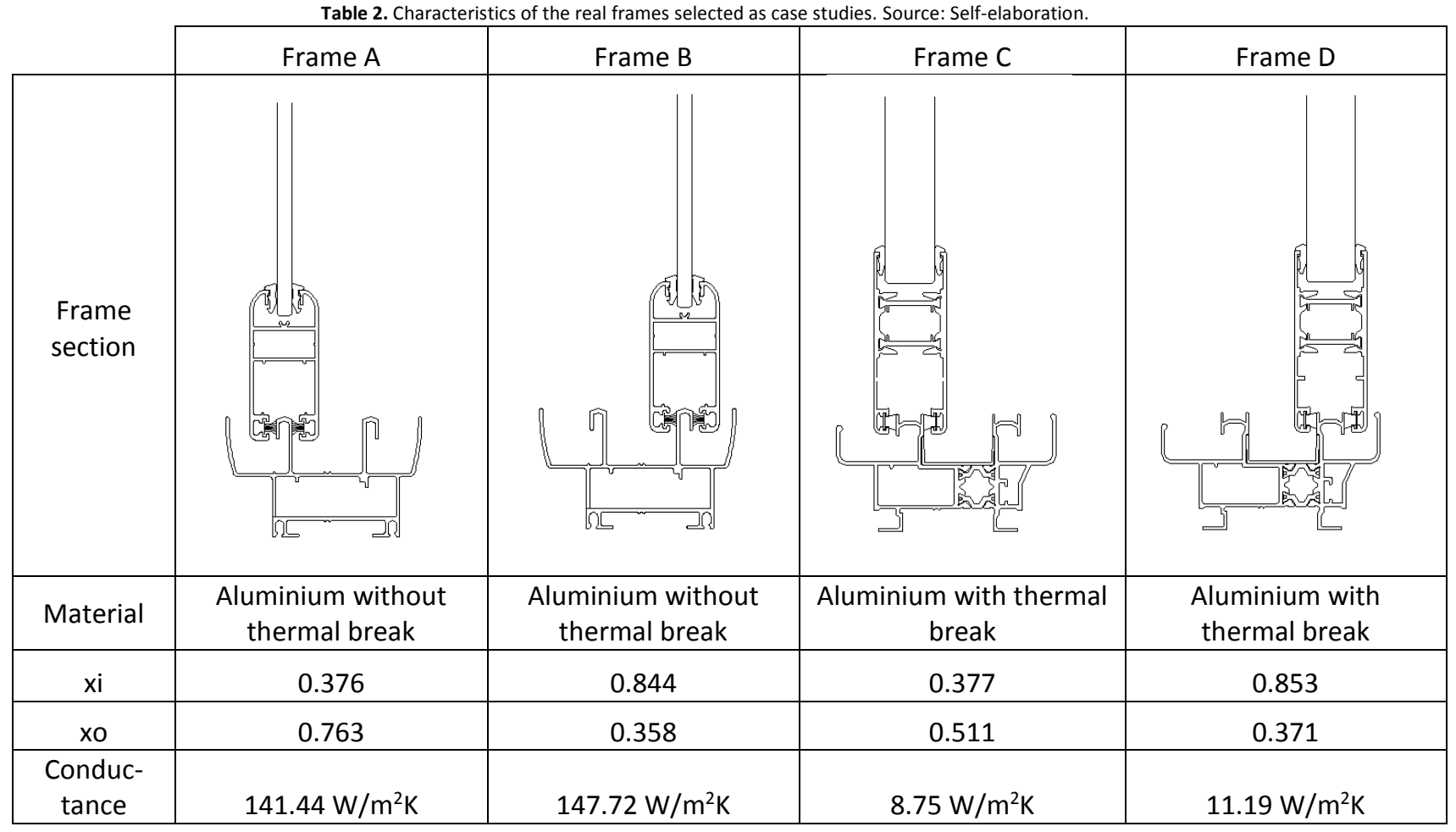

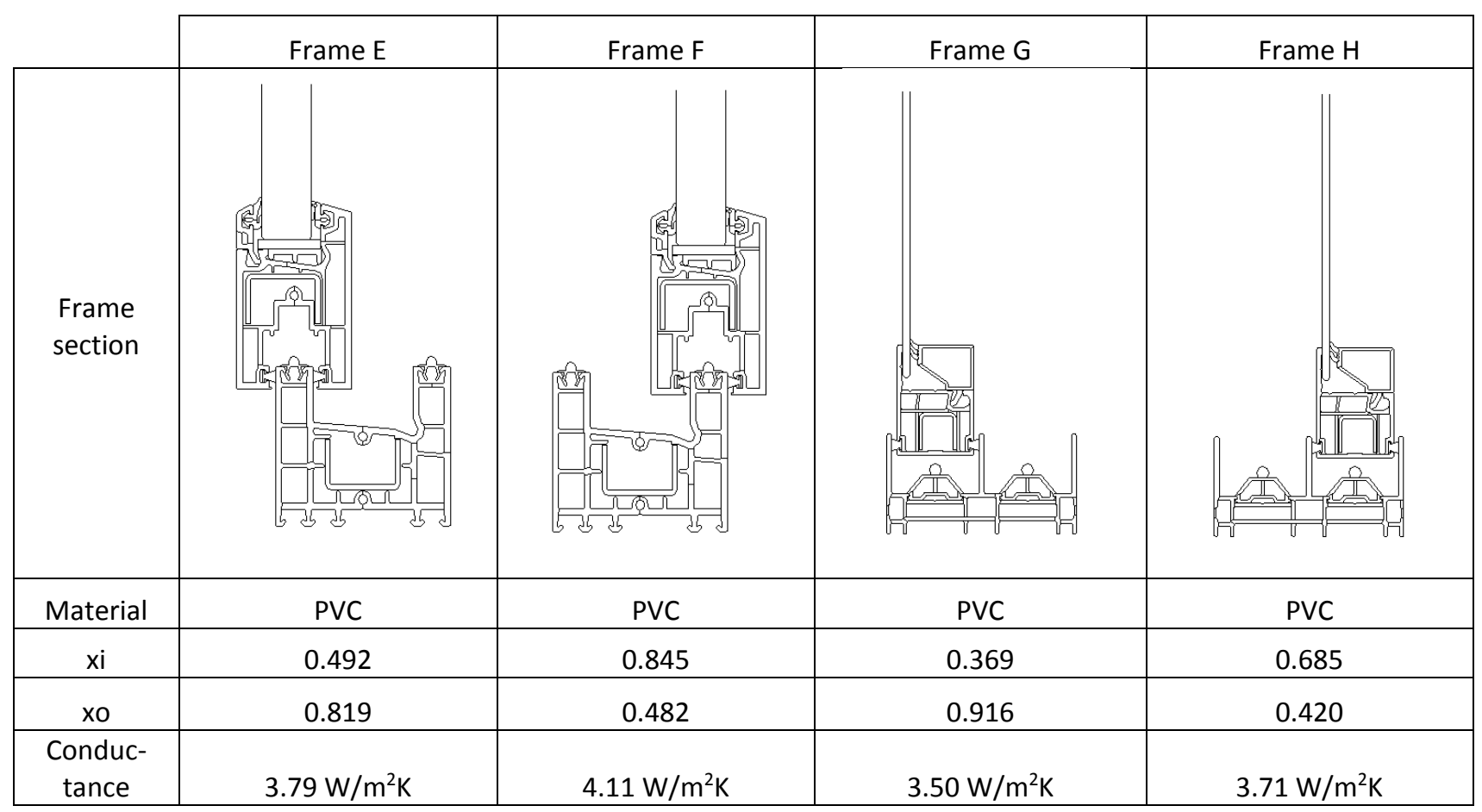

Table 3. Environmental conditions considered in this work. Source: Self-elaboration.

\begin{tabular}{lcccccc}
\hline $\begin{array}{l}\text { Environmental } \\
\text { conditions }\end{array}$ & $\mathrm{T}_{\mathrm{i}}\left({ }^{\circ} \mathrm{C}\right)$ & $\mathrm{T}_{\mathrm{ri}}\left({ }^{\circ} \mathrm{C}\right)$ & $\mathrm{h}_{\mathrm{i}}\left(\mathrm{W} / \mathrm{m}^{2} \mathrm{~K}\right)$ & $\begin{array}{c}\mathrm{T} \text { o } \\
\left({ }^{\circ} \mathrm{C}\right)\end{array}$ & $\begin{array}{c}\mathrm{T}_{\mathrm{ro}} \\
\left({ }^{\circ} \mathrm{C}\right)\end{array}$ & $\mathrm{h}_{\circ}\left(\mathrm{W} / \mathrm{m}^{2} \mathrm{~K}\right)$ \\
\hline $\mathrm{C} 1$ & 21 & 21 & 3.29 & -18 & -18 & 26 \\
$\mathrm{C} 2$ & 21 & 21 & 3.29 & 15 & 9 & 15 \\
$\mathrm{C} 3$ & 21 & 21 & 3.29 & 28 & 24 & 10 \\
\hline
\end{tabular}


Figure 1 shows the relative differences between Uf0 and Uf1 obtained for each rectangular frame, as a function of $\eta$, for the different environmental conditions. Figure 2 shows relative differences between UfO and Uf1 values for frames A to $\mathrm{H}$. In all cases, Uf1 is taken as the reference value.

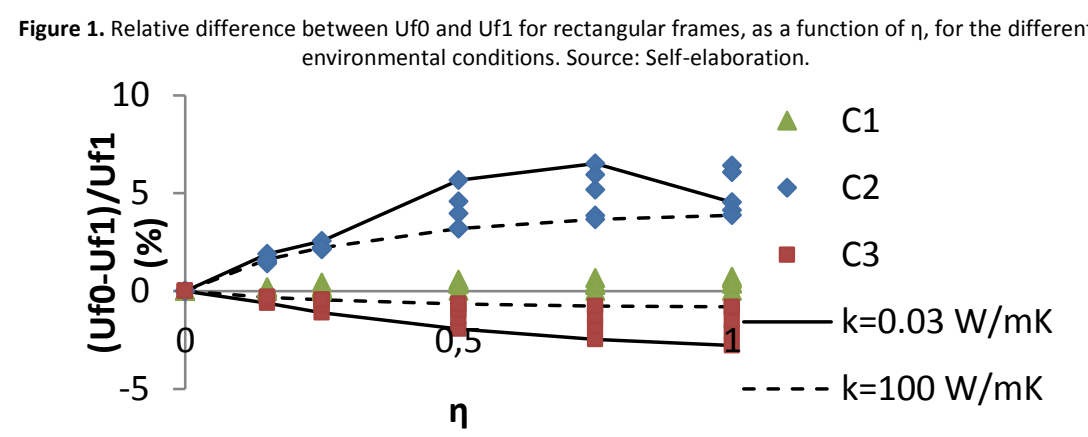

Figure 2. Relative difference between Uf0 and Uf1 for real frames, for the different environmental conditions. Source: Self-elaboration.

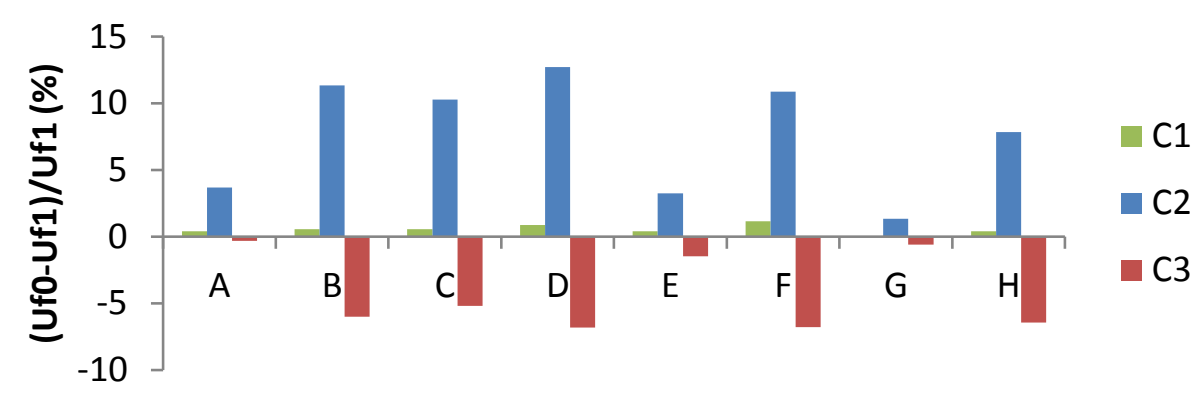

It appears that relative differences between UfO and Uf1 strongly depend on environmental conditions. In conditions $\mathrm{C} 1$, they are negligible (less than $1.2 \%$ ), including for real frames, which have a much more complex geometry. In conditions C2, UfO values are higher than Uf1 values, and the relative difference between UfO and Uf1 is comprised between 0 and $6.5 \%$ for rectangular frames, and are up to $12.7 \%$ in the case of real frames (see case D Figure 2). While, in conditions $\mathrm{C} 3$, Uf1 values are higher than UfO values, and the relative difference is comprised between 0 and $-2.78 \%$ for rectangular frames, and are up to $-6.82 \%$ in the case of real frames (see case D Figure 2 ).

The results obtained in conditions C1 are striking. The little difference between UfO and Uf1 values in those environmental conditions demonstrates that radiative effects have very little influence on the frame heat balance. This is because the convective coefficient is very high $\left(26 \mathrm{~W} / \mathrm{m}^{2} \mathrm{~K}\right)$, thus masks the radiative effects. This can be seen in Equation 3, which describes the dependence of frame U-factor on film coefficients (de Gastines et al., 2016):

$$
\frac{1}{U_{f}}=\frac{1}{K_{f}}+\frac{x_{i}}{h_{c i}+h_{r i}}+\frac{x_{o}}{h_{c o}+h_{r o}}
$$

Where Uf is the frame $\mathrm{U}$-factor, $\mathrm{Kf}$ is the frame conductance, $\mathrm{h}_{\mathrm{ci}}$ and $\mathrm{h}_{\mathrm{co}}$ are the inside and outside convective coefficients, and $h_{r i}$ and $h_{r o}$ are the inside and outside radiative coefficients.

In this equation, we see that when $h_{c o}$ is much higher than $h_{r o}$, variations of $h_{\text {ro }}$ produce very little variation in the term

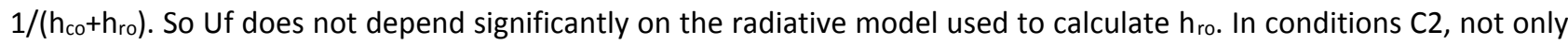
the convective coefficient is lower $\left(15 \mathrm{~W} / \mathrm{m}^{2} \mathrm{~K}\right)$ but the outside surface temperature $\mathrm{T}_{\text {so }}$ is very close to the air temperature $T_{0}$, whereas there is a higher temperature difference between $T_{\text {so }}$ and the mean radiant temperature $T_{r o}$. As a result, radiative effects largely predominate over convective effects, which explains why the overestimate of radiative exchanges produces higher errors in Uf calculation. In conditions $\mathrm{C} 3$, the convective coefficient is still lower $\left(10 \mathrm{~W} / \mathrm{m}^{2} \mathrm{~K}\right)$, but the temperatures distribution is such that convective and radiative effects are more balanced, hence the error in Uf calculation due to radiative model simplification is more attenuated. 
The sign difference between the different cases can be explained by environmental conditions. As illustrated in Table 4, in conditions $C 1$ and $C 2$, we have $T_{r o}<T_{\text {so }}$ and $T_{0}<T_{i}$, thus the outside radiative heat flow is oriented in the same way as the heat flow due to air temperature difference $\left(T_{i}-T_{0}\right)$. When the blackbody radiation model is used, radiative exchanges are overestimated, and the heat flow as well. The resulting $U_{f}$ value (UfO) is higher than Uf1 (obtained using a detailed radiation model). In contrast, in conditions C3 (summer conditions), the outside air temperature To is higher than the inside temperature $T_{i}$ (heat flow from outside to inside) but the mean radiant temperature $T_{\text {ro }}$ is lower than the outside surface temperature $\mathrm{T}_{\text {so, }}$ which means that the radiative heat flow is oriented in the opposite way to the total heat flow. As a result, the total heat flow magnitude is underestimated when overestimating the outside radiative heat flow, which results in UfO being lower than Uf1.

Table 4. Schematic illustration of heat flow directions according to environmental conditions. Depending on season, overestimations of outside radiative exchanges produce over- or underestimations of total heat flux through window frames. Source: Self-elaboration.

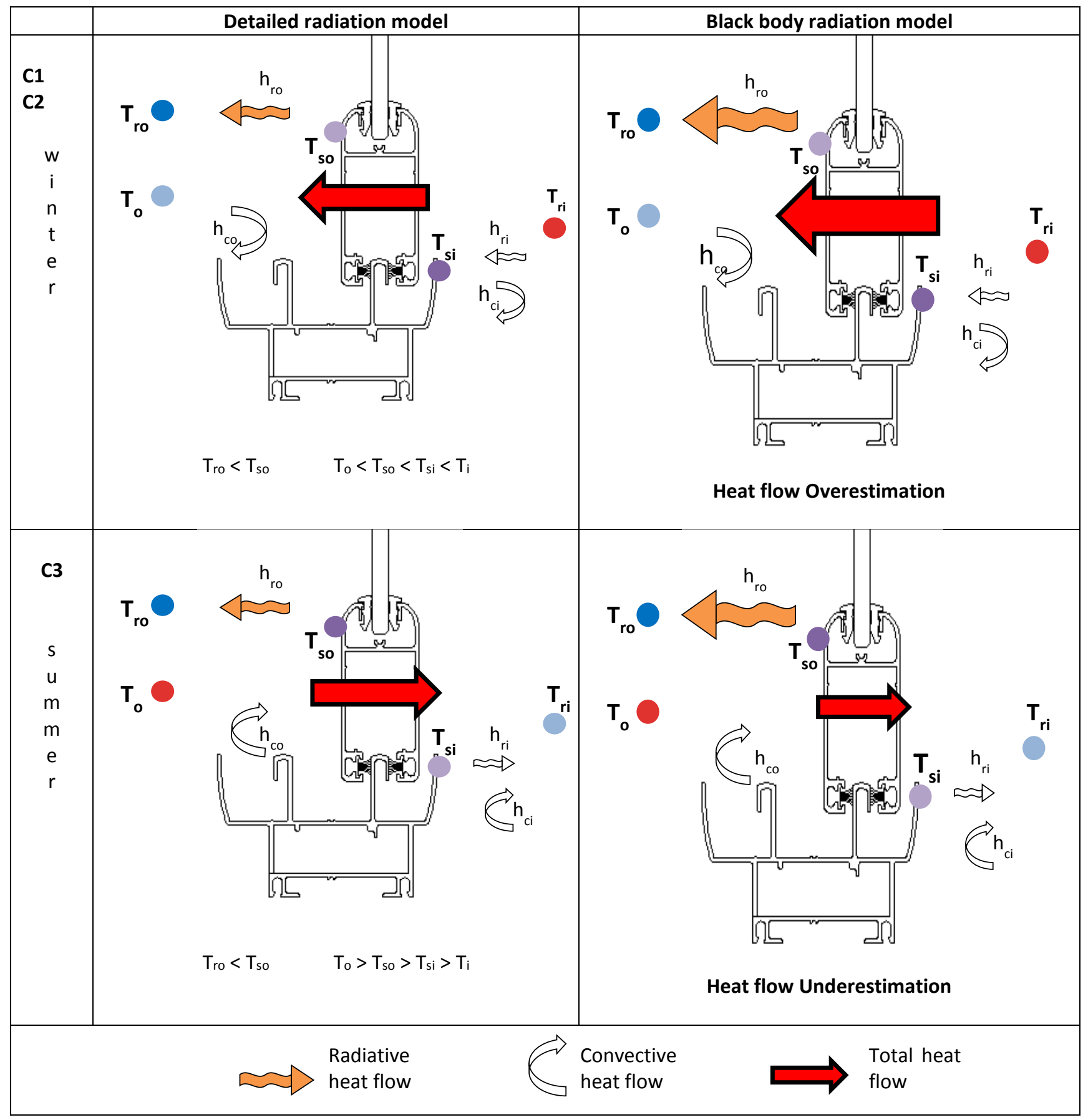

It can be observed that the relative differences between Uf0 and Uf1 increases with $\eta$. In the particular case $\eta=0$ (without any inside or outside projections), the difference is zero, which was a foreseeable result since in this case, the frame sees the surroundings with a view factor of 1 , thus the THERM blackbody and detailed radiation models are equivalent. 
As $\eta$ increases (i.e. as the frame projections increase), the relative differences between UfO and Uf1 rise and are increasingly dependent on the conductivity value.

In the case of real frames, the estimates are better for frames $A, E$ and $G$, than for the others. The error does not appear to be related to frame material or conductance, but rather to the outside compactness factor $x_{0}$. Frames $A, E$ and $G$ have a compact outside profile ( $x_{0}$ close to 1 ) which implies that their thermal behaviour is less sensitive to the radiative model employed onthe outside boundary; whereas the other frames have a more irregular outside profile, including many self-viewing surfaces. Figure 3 shows the relative differences between UfO and Uf1 for all the case studies, as a function of $x_{0}$, calculated in the case of rectangular frames as $x_{o}=\frac{1}{1+\eta}$. A clear correlation can be observed between the error due to the use of the simplified blackbody radiation model and the compactness factor.

Discussion

The comparison between UfO values (calculated with a blackbody radiation model on the outside) and Uf1 values (calculated with a detailed radiation model on both sides) showed significant differences between both values, especially for non-planar frames (up to $12.7 \%$ ) and under temperate environmental conditions. Using a blackbody radiation model leads to heat loss overestimation in winter and heat gain underestimation in summer. This could encourage the use of highly conservative windows in climates where cooling loads are actually much higher than heating loads, and where shading and ventilation would be more efficient (and affordable) strategies.

It was observed that the magnitude of this difference depends on the respective weight of radiative and convective exchanges at the outside surface of the window frame. When using a high convective coefficient, the difference is close to zero. This is why using a simplified radiation model combined with a convective coefficient of $26 \mathrm{~W} / \mathrm{m}^{2} \mathrm{~K}$ on the outside boundary, as indicated in NFRC procedure, will not produce significant estimation errors. However, for an analysis under real conditions (dynamic simulation) the convective coefficient may be much lower. Also, radiative exchanges may be particularly significant in some cases, for example in the urban heat island context previously mentioned (Alchapar \& Correa, 2016). In these conditions, the use of a detailed radiation model on both sides of the window is critical.

Figure 3. Relative difference between Uf0 and Uf1 for all case studies, as a function of xo, for the different environmental conditions. Source: Self-elaboration.

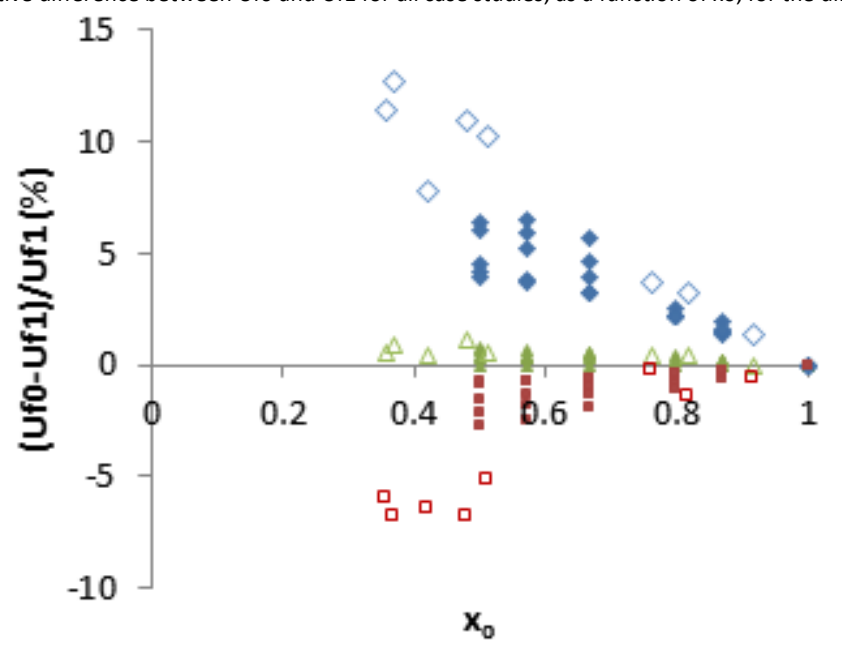

$\triangle \mathrm{C} 1$ - rectangular frames

$\triangle \mathrm{C} 1$ - slider frames

- C2 - rectangular frames

$\diamond \mathrm{C} 2$ - slider frames

- C3 - rectangular frames

- C3 - slider frames

Although the sets of conditions C2 and C3 have a fair probability of occurrence in the centre and north of Argentina, they were selected theoretically for the purpose of the present study. An in-depth analysis of climatic zoning is required for establishing an adequate window rating system in the country.

Furthermore, the difference between UfO and Uf1 increases with the shape factor $\eta$, which means that the error is higher for highly non-planar frames. Hence, it is particularly important to use the detailed radiation model on both sides when the frame is non-planar. ISO 15099 considers a window as non-planar when its ratio of total to projected boundary surface area on the internal/external side is greater than 1.25. However, for consistency, we recommend to always use the detailed radiation model on both sides of the frame. 
The results of this study show that, in order to maximise the accuracy of non-planar frames thermal transmittance calculation in any environmental conditions, it is necessary to use a two-dimensional simulation program and use a detailed radiation model on both sides of the frame. The use of a simplified radiation model in part or all of the frame surfaces (as indicated in ISO 10077-2 and ISO 15099) can introduce important errors (over 10\%) in frame U-factor calculation, especially for environmental conditions in which radiative exchanges predominate over convection.

\section{References}

Alchapar, N. L., \& Correa, E. N. (2016). The use of reflective materials as a strategy for urban cooling in an arid "OASIS" city. Sustainable Cities and Society, 27, 1-14.

Andaloro, A. P. F., Salomone, R., loppolo, G., \& Andaloro, L. (2010). Energy certification of buildings: A comparative analysis of progress towards implementation in European countries. Energy Policy, 38(10), 5840-5866.

Asdrubali, F., Baldinelli, G., \& Bianchi, F. (2013). Influence of cavities geometric and emissivity properties on the overall thermal performance of aluminum frames for windows. Energy and Buildings, 60, 298-309.

Avasoo, D. (2007). The European window energy labelling challenge. Proceedings of the European Council for an Energy Efficient Economy (ECEEE) Summer Study, 4-9.

Blanusa, P., Goss, W. P., Roth, H., Weitzmannn, P., Jensen, C. F., Svendsen, S., \& Elmahdy, H. (2007). Comparison between ASHRAE and ISO thermal transmittance calculation methods. Energy and Buildings, 39(3), 374-384.

Cordero, B., García-Santos, A., \& Overend, M. (2015). Thermal performance of novel frame-integrated unitised curtain wall. Revista de la Construcción, 14(1), 23-31.

De Gastines, M., Villalba, A., \& Pattini, A. (2014). Determinación del Factor K de ventanas. Utilización de programas de simulación de precisión para evaluar el impacto del diseño de marcos y de las condiciones climáticas. Avances En Energías Renovables Y Medio Ambiente, 18, 08.35-08.42.

De Gastines, M., Villalba, A., \& Pattini, A. (2016). Improved model for the thermal performance calculation of non-planar window frames for building simulation programs. Journal of Building Performance Simulation, 1-15.

Duer, K., Svendsen, S., Moller Mogensen, M., \& Birck Laustsen, J. (2002). Energy labelling of glazings and windows in Denmark: calculated and measured values. Solar Energy, 73(1), 23-31.

Griffith, B., Curcija, D., Turler, D., \& Arasteh, D. K. (1998). Improving computer simulations of heat transfer for projecting fenestration products: using radiation view-factor models. ASHRAE Transactions-American Society of Heating Refrigerating Airconditioning Engin, 104(1), 845-855.

Hilderson, W. (2011). Therm 6.3 validation according to EN ISO 10211:2007. Retrieved December 19, 2016. Available online at: http://www.bouwdetails.be/THERM_Validatie/Therm6.3_10211_Validation.pdf

IRAM. (2012). N 11603: Acondicionamiento térmico de edificios. Instituto Argentino de Normalización y Certificación, Buenos Aires, Argentina.

ISO. (2003a). 10077-2: Thermal performance of windows, doors and shutters--Calculation of thermal transmittance--Part 2: Numerical method for frames (ISO 10077-2: 2003). CEN, Brussels, Belgium.

ISO. (2003b). 15099. 2003. Thermal performance of windows, doors and shading devices--detailed calculations. International Organization for Standardization, Geneva, Switzerland.

Karlsson, J., Karlsson, B., \& Roos, A. (2001). A simple model for assessing the energy performance of windows. Energy and Buildings, 33(7), 641-651.

Kiss, B., \& Neij, L. (2011). The importance of learning when supporting emergent technologies for energy efficiency-A case study on policy intervention for learning for the development of energy efficient windows in Sweden. Energy Policy, 39(10), 6514-6524.

Lamberts, R., Goulart, S., Carlo, J., \& Westphal, F. (2007). Regulation for energy efficiency labeling of commercial buildings in Brazil. In 2nd PALENC Conference and 28th AIVC Conference on Building Low Energy Cooling and Advanced Ventilation Technologies in the 21st Century, Crete Island.

NFRC. (2004). NFRC 100-2004, Procedure for Determining Fenestration Product U-Factors. National Fenestration Rating Council, Greenbelt, MD: National Fenestration Rating Council.

Nielsen, T. R., Duer, K., \& Svendsen, S. (2001). Energy performance of glazings and windows. Solar Energy, 69, 137-143.

Noyé, P. A., Laustsen, J. B., \& Svendsen, S. (2004). Calculating the heat transfer coefficient of frame profiles with internal cavities. Nordic Journal of Building Physics, 3, 1-7.

Pattini, A., Correa, E., Villalba, A., Fernández Llano, J., \& de Gastines, M. (2014). Eficiencia energética de ventanas. Índices para su clasificación y etiquetado energético. In $5^{\circ}$ Congreso Internacional Solar Cities - Energía en las ciudades: Innovación frente al cambio climático. Buenos Aires.

Pattini, A. E., Villalba, A., Correa, E., \& Llano, J. C. F. (2013). Análisis de la certificación de eficiencia energética de ventanas. Índices termo-lumínicos. Encuentro Latinoamericano de Uso Racional y Eficiente de la Energía - ELUREE2013. Buenos Aires, Argentina.

Pérez-Lombard, L., Ortiz, J., González, R., \& Maestre, I. R. (2009). A review of benchmarking, rating and labelling concepts within the framework of building energy certification schemes. Energy and Buildings, 41(3), 272-278. 
RDH Building Engineering. (2014). International Window Standards. Vancouver: RDH Building Engineering.

Robin, M., Kohler, C., Curcija, D., Zhu, L., Vidanovic, S., Czarnecki, S., \& Aratesh, D. (2011). THERM 6.3/WINDOW 6.3 NFRC Simulation Manual. California, USA. 